\title{
Clinicopathological Evaluation of the Patients with Hoarseness of Voice
}

\author{
Durgesh Gajendraํㅜ Archana Tirkey² \\ ${ }^{1}$ Department of ENT, Pt. JNM Medical College, Raipur, Chhattisgarh, India. \\ ${ }^{2}$ Department of ENT, Pt. JNM Medical College, Raipur, Chhattisgarh, India.
}

\section{ABSTRACT}

\section{BACKGROUND}

Hoarseness is one of the commonest symptoms which brings the patient to physician. Any change in quality of voice must be evaluated thoroughly and promptly as it may underlie some infective or neoplastic lesion which can be managed better if diagnosed at an early stage.

\section{METHODS}

The study was conducted in Pt. J.N.M. Medical College, Raipur, for period of 1.5 years in which 81 patients with hoarseness were selected. After complete general and ENT examination, required investigations were done. Data was collected, tabulated and compared. Out of the total of 81 patients, 58 were males and 23 were females. Carcinoma laryngo-pharynx was found to be the most common cause of hoarseness. Most of the cases were from middle age group i.e. 50 to 60 years. Associated tobacco addiction in any form was very common in all the patients.

\section{RESULTS}

Hoarseness of voice can be an alarming symptom in adult patients, particularly when it is present in males with chronic history of addiction. One should be very cautious during investigations as it leads to malignancy most of the time. Early diagnosis and treatment give good prognosis and better outcome to the patient.

\section{CONCLUSIONS}

Hoarseness of voice is just a symptom with a very diverse aetiology. Proper diagnosis through detailed history and prompt examination leads to early diagnosis and management as well.

\section{KEY WORDS}

Hoarseness, Stroboscopy, Direct Laryngoscopy
Corresponding Author: Dr. Archana Tirkey, H. No. 273, Ward No. 4, RES. Colony, Bacheli, Dantewada-494553, Chhattisgarh, India.

E-mail: archanatirkey.a@gmail.com

DOI: $10.14260 / j e m d s / 2020 / 118$

Financial or Other Competing Interests: None.

How to Cite This Article:

Gajendra D, Tirkey A. Clinicopathological evaluation of the patients with hoarseness of voice. J. Evolution Med. Dent. Sci. 2020;9(08):524-526, 10.14260/jemds/2020/118

Submission 19-12-2019, Peer Review 26-01-2020,

Acceptance 05-02-2020,

Published 24-02-2020.

\section{(i)}




\section{BACKGROUND}

As voice is the primary means of communication, any change in its quality is noticeable and brings the patient to ENT specialist. Hoarseness is a term referring to abnormal voice changes. Hoarseness is one of the commonest symptoms in Otolaryngologic practice and is invariably the earliest manifestation of large varieties of conditions directly or indirectly affecting the voice apparatus ${ }^{1}$. Hoarseness can be defined as breathy, strained, rough or raspy voice having higher or lower pitch. It indicates diseases ranging from absolute benign infective cause to the most malignant reasons. The causes of hoarseness are determined after obtaining a detailed medical history of the circumstances preceding the onset of hoarseness followed by general physical examination and thorough complete ENT examination. The latter may include visualisation and examination of the larynx by indirect laryngoscopy, flexible laryngoscopy and/ or direct laryngoscopy and stroboscopy2. The hoarseness can be divided into acute or chronic. The acute onset is more common and mainly causes are inflammatory like acute laryngitis whereas other causes could be smoking, vocal abuse, laryngeal trauma or head and neck surgeries example: - thyroid surgery. The chronic onset is mainly caused by vocal nodule, vocal polyp, laryngeal papillomatosis, tumour of vocal cord, functional dysphonia, laryngopharyngeal reflux disease, postnasal drip, neoplasm of thyroid, oesophagus, lung, chronic granulomatous disease and systemic disease like diabetes mellitus ${ }^{3}$. The chronic hoarseness may underlie some serious disease that's why it should be ignored and properly evaluated for cause. Lack of awareness among general population for timely referral and poor diagnostic facilities in peripheral hospitals also play vital role in higher incidence and late presentation to the ENT specialist. Thus, any patient with chronic hoarseness in absence of an apparent benign cause must be evaluated thoroughly, cautiously and diagnosed as early as possible. Voice abuse, smoking and drinking habits, environmental pollution definitely influences the incidence of hoarseness.

We wanted to assess the aetiology and clinical profile of patients with hoarseness.

\section{METHODS}

The study was performed in Pt. J.N.M. Medical College, Raipur with the approval from institutional ethics committee for the period of 1.5 years. Total 81 patients were selected who attended ENT OPD with complain of chronic hoarseness (change in voice for more than 2 weeks). After consent, detailed personal, occupational, family, drug, disease and addiction history was taken. Special consideration was given to occupational or addiction history as some occupations (teachers, singers, hawkers) are at risk to develop voice disorders and addiction (smoking, tobacco, alcohol consumption) tend to predispose neoplastic changes. Thorough general and ENT examination was performed and required investigations like haemogram, X-ray chest, renal function tests were done. Direct laryngoscopy, stroboscopy, fine needle aspiration cytology, ultrasonography or CT Scan is advised if required.

\section{Exclusion Criteria}

1. Speech and articulation disorders.

2. Voice disorders caused by CNS abnormality like Guillain barre syndrome.

3. Functional dysphonia/aphonia.

4. Patient who were uncooperative and not granted consent for the study.

\section{Sample Size}

Sample size was calculated as follows-

$$
n=\underline{1-a / 2 p(1-p)}
$$

Where $\mathrm{p}=$ expected precision, $\mathrm{d}=$ absolute precision, 1 $\mathrm{a} / \mathrm{p}=$ desired confidence interval.

Prevalence of hoarseness is $30 \%$; we assume precision $=10$; confidence interval $=95$; therefore, sample size $=81$

\section{Statistical Analysis}

All the data was compiled in MS excel and checked for completion and correction.

\section{RESULTS}

\begin{tabular}{|c|c|c|c|}
\hline Sl. No. & Sex & No. of Cases & Percentage \\
\hline 1. & Male & 58 & 71.60 \\
\hline 2. & Female & 23 & 28.40 \\
\hline 3. & Total & $\mathbf{8 1}$ & $\mathbf{1 0 0}$ \\
\hline \multicolumn{4}{|c|}{ Table 1. Sex Wise Distribution of the Patients } \\
\hline
\end{tabular}
than females $(28.40 \%)$

\begin{tabular}{|c|c|c|c|}
\hline Sl. No. & Causes & No. of Cases & Percentage \\
\hline 1. & Ca. Larynx & 27 & 33.33 \\
\hline 2. & Vocal nodule & 18 & 22.22 \\
\hline 3. & Laryngitis & 12 & 14.81 \\
\hline 4. & VC paralysis & 10 & 12.35 \\
\hline 5. & Vocal Polyp & 5 & 6.17 \\
\hline 6. & Others (Oedema, Papilloma etc.) & 9 & 11.11 \\
\hline \multicolumn{4}{|c|}{ Table 2. Causes of Hoarseness } \\
\hline $\begin{array}{l}\text { In this study shows carcinoma larynx (33.33\%) is the most common cause of } \\
\text { hoarseness followed by vocal nodule (22.22\%), laryngitis (14.81\%) and others } \\
\text { respectively }\end{array}$ \\
\hline
\end{tabular}

\begin{tabular}{|c|c|c|c|}
\hline Sl. No. & Factors & No. of Cases & $\mathbf{\%}$ \\
\hline 1. & Addiction (Smoking/ Tobacco/Alcohol) & 51 & 62.96 \\
\hline 2. & Vocal abuse & 21 & 25.93 \\
\hline 3. & GERD & 18 & 22.22 \\
\hline 4. & URI & 10 & 12.35 \\
\hline 5. & Trauma & 5 & 6.17 \\
\hline \multicolumn{3}{|c|}{ Table 3. Predisposing Factors of Hoarseness } \\
\hline
\end{tabular}

Addiction (smoking/ tobacco/ alcohol) was found to be most common predisposing factor for hoarseness of voice followed by vocal abuse and GERD.

\section{DISCUSSION}

In our study the male: female was 2.52: 1 . Baitha at el (2002) observed male: female 2:1.4 Sindhu at el (2018) found male: female $2: 1 .^{5}$ In our study also there is male preponderance. Maximum patients were from the age group of 50 to 60 years 
(32\%), followed by 40-50 years (19.75\%) and $60-70$ years (17.8\%). Amarnath S.B. at el 2019 study shows maximum cases $32.65 \%$ from the age group 51-60 years ${ }^{6}$. Baitha at el (2002) showed $4^{\text {th }}$ decade was the most commonly affected age group, i.e. similar to our study. Dysphagia (23.46\%) was the most common associated symptom inpatients, followed by throat discomfort (17.28\%), cough (16.5\%), neck swelling (14.81\%). SmitaSoni at el (2017) study shows dysphagia was the major associated complain (51\%).Addiction of tobacco and alcohol was the prime predisposing factor found to be associated with (44.4\%). Vocal abuse was second most common cause for hoarseness (25.93\%), followed by GERD (22.22\%), Smoking (20.99\%) and URI (12.35\%). Baitha at el (2002) found smoking in 25\%, Smitasoni et al (2017) found in $60 \%$, which is similar to our study. Vocal abuse was found in $25.93 \%$ of patients in our study while in Banjara at el (2011) study it was $31 \%{ }^{1}$. Carcinoma of larynx was the prime cause of hoarseness in our study which included 27 patients (33.3\%), followed by vocal nodule (18 patients), chronic laryngitis (14 patients), vocal polyp (5 patients) and Reinke's Oedema (4 patients). Malignancy of larynx was found as prime cause in other studies like Amarnath at el 2019 (40\%), Sindhu B.S. at el 2018 (56\%) and Gupta A at el 2018 (16\%).7 The result is very similar to our study. Vocal nodule was present in $22.22 \%$ cases in our study. Similarly it was second most common cause of Hoarseness in studies of Baitha at el $12.72 \%$ and Munjal at el 2016 (20\%). ${ }^{8}$ All patients were examined by indirect laryngoscopy (98\%), direct laryngoscopy (71.60\%), microlaryngoscopic biopsy (35.80\%), stroboscopy (24.69\%) followed by FNAC, USG and CT scan of head and neck.

\section{CONCLUSIONS}

Hoarseness of voice, mainly of chronic type may underlie variety of diseases ranging from infective to neoplastic pathologies. Proper diagnosis through detailed history and prompt examination leads to early diagnosis and treatment as well, thus, reducing the morbidity and mortality of the patient and also improves the quality of life.

\section{REFERENCES}

[1] Banjara H, Mungutwar V, Singh D, et al. Hoarseness of voice: retrospective study of 251 cases. International Journal of Phonosurgery and Laryngology 2011;1(1):217.

[2] Rosen CA, Anderson D, Murry T, et al. Evaluating Hoarseness: keeping your patient's voice healthy. American Family Physician 1998;57(11):2775-82.

[3] Soni S, Chouksey S. A study of clinicopathological profile of patients of hoarseness of voice presenting to tertiary care hospital. Indian Journal Otolaryngology and Head \& Neck Surgery 2017;69(2):244-7.

[4] Baitha S, Raizada RM, Singh AKK, et al. Clinical profile of hoarseness of voice. Indian J of Otolaryngol Head \& Neck Surg 2002;54(1):14-8.

[5] Sindhu BS, Jayaprabha S. A descriptive study of aetiopathological evaluation of hoarseness: our experience. International Journal of Otolaryngology and Head \& Neck Surgery 2018;4(2):356-61.

[6] Amarnath SB, Purushotham K. Aetiopathological study of hoarseness of voice: a clinical study. International Journal of Otolaryngology Head and Neck Surgery 2019;5(1):91-5.

[7] Gupta A, Jamwal PS. Clinical study of 100 cases of hoarseness of voice: hospital based study. International Journal of Otolaryngology and Head \& Neck Surgery 2018;4(6):1-4.

[8] Munjal M, Ghera B. Hoarseness of voice - an institutional study. International Journal of Otolaryngology and Head \& Neck Surgery 2016;2(4):220-3. 